\title{
Determination of the cohesion, powder flow speed dependency and caking tendency of cocoa powders
}

\author{
*1,2 Mahmut Doğan and ${ }^{1}$ Duygu Aslan Türker \\ ${ }^{1}$ Department of Food Engineering, Faculty of Engineering, Erciyes University, Kayseri, Turkey \\ ${ }^{2}$ TAGEM Food Analysis Center Co., Erciyes University Technopark Area, Kayseri, Turkey
}

\begin{abstract}
Cocoa is one of the most popular foodstuffs known for centuries and cocoa powders are particularly exposed to caking, a phenomenon of agglomeration of solid particles that disrupt powder functionality. The study aimed to identify the main powder flow characteristics such as caking, cohesion and powder flow speed dependency of cocoa powders, according to their fat content. The loose and tapped bulk density, as well as Carr ratio of cocoa powders, was determined as bulking properties for comparing and interpreting the flowability. The caking was observed in all three samples. With increasing fat content, a decrease in the powder flowability was detected. The mean cake strength of the low fat, reduced fat and full-fat cocoa powders was recorded as $110.42 \pm 1.71 ; 164.175 \pm 1.75$ and $207.96 \pm 0.93$, respectively. These results suggest that the fat contents of the food powders may be a useful parameter to describe the powder flowability.
\end{abstract}

Key words: powder flowability, caking, cocoa, cohesion

*Corresponding author: Address: Faculty of Engineering, Department of Food Engineering, Erciyes University, 38039, Kayseri, TURKEY. E-mail address: dogan@erciyes.edu.tr, Phone: +903522076666/32751 


\section{Introduction}

Cocoa is one of the most popular foodstuffs known for centuries and is derived from cocoa bean plants. Cocoa plants have many differences with products such as cocoa butter and cocoa powder. Different methods are utilized in the world to produce cocoa. Based on these methods, cocoa could be natural, defatted or alkalized. It is possible to find various products containing cocoa in numerous areas, such as cocoa cakes as a foodstuff and crèmes containing cocoa butter as pharmaceutical material. In addition, it is the main ingredient of chocolate which is one of the most popular snacks in the world. 78-90\% of cocoa butter is obtained by pressing high-fat cake (22\% fat) and low-fat cake (10\% fat) in general. Eventually, the cocoa cake is milled into smaller pieces and milled to obtain the desired type of cocoa powder [1]. In general, cocoa beans contain $54 \%$ fat, $12 \%$ protein, $5 \%$ moisture, $1.46 \%$ ash, $1.09 \%$ theobromine and $0.44 \%$ caffeine. Differences in the origin of cocoa beans can be observed in the composition. For example, cocoa beans of West African origin have a fat content of approximately 58\%, while cocoa beans originating from Mexico and Indonesia have approximately 53\% fat [2]. The change in the cocoa composition has led to prominent changes in powder flow properties of both the cocoa and the products produced from the cocoa.

Powder caking is a challenging phenomenon affecting a wide range of materials, and various mechanisms are responsible for the onset of caking. In order to successfully predict the tendency to caking, it is essential that the mechanisms underlying the driving change to understand. A small change in a component within a complex mixture can cause significant changes in the final product. It is recommended to identify which material is problematic and replace it with more appropriate components; however, this is not always an option and the ability to understand the effect of the components on a mixture is desirable [3]. Foster, Bronlund [4] studied the effect of milk powders containing amorphous lactose and showed that if there is enough fat on the particle surface, caking would occur by crystallization of the fat. Work by Perez-Munoz and Flores [5], represented that the high-fat content in spray-dried soy milk decreased flowability. In contrast, Fitzpatrick, Hodnett [6] showed that the presence of fat reduces the tendency of the amorphous material to cake since hydrophobic fat prevents the formation of aqueous capillary bridges. These studies in the literature demonstrated the difficulty of understanding caking mechanisms. In one situation, it was observed that the crystallizing fat increased caking; on the contrary, its hydrophobic nature reduced caking. Accordingly, it is necessary to investigate the flowability of food products, especially food components. To date, no study has investigated the powder flow properties of cocoa powder which had different fat compositions. Therefore, the purpose of this study was to examine some important flow characteristics such as cohesion coefficient, powder flow speed dependency and caking behavior of the cocoa as it is the most popular food components.

\section{Materials and Method}

Low-fat cocoa (10-12 \% fat) was provided by Bayrak Food Co., Turkey, reduced-fat cocoa (about $15-17 \%$ fat) and high-fat cocoa (20-22\% fat) was from Altınmarka, Turkey.

\subsection{Tapped, Loose Bulk density, Carr index, and Hausner Ratio}


The loose bulk density $\left(\rho_{\text {bulk }} \mathrm{g} / \mathrm{cm}^{3}\right.$ ) analysis was calculated as filling and weighing of $25 \mathrm{~mL}$ of powder product into stable and known glassware. Tapped bulk density was calculated as the volume measurement and ratio $\left(\rho_{\text {tapped }} \mathrm{g} / \mathrm{cm}^{3}\right)$ after manually tapping the same sample in 180 times per second on a hard surface [7].

Carr index values were calculated according to the difference between the compressed density and the bulk density values [8] and the Hausner ratio was calculated as previously described by Jan, Rafiq [9].

\subsection{Powder Flowability Tests}

In powder flow analysis, cohesion, powder flow speed dependency (PFSD test) and caking test were performed. For the analysis, a glass cylinder $(120 \mathrm{~mm}$ height and $50 \mathrm{~mm}$ inside diameter with vertical and $48 \mathrm{~mm}$ diameter) and a special blade (moving in the horizontal and vertical plane with a height of $10 \mathrm{~mm}$ ) were used with the a special powder rheometer (Stable Micro System (TA-XT2 Plus, UK).

The caking analysis is based on the compaction of the powder sample in the cylinder and the calculation of the cylinder height. For this purpose, the powder sample is compressed with a repeated cycle of five times and the cake strength was calculated.

The PFSD test consisted of 5 sets and 2 cycles with increasing speeds of 10, 20, 50 and 100 $\mathrm{mm} . \mathrm{s}^{-1}$. The compaction coefficient in the cycles was calculated from the positive area under the force/distance curve. During the analysis, the final cycle takes place with $10 \mathrm{~mm} . \mathrm{s}^{-1}$ and the ratio of the compaction coefficients and the flow stability index were determined.

The cohesion test was performed to obtain cohesion index and cohesion coefficient values in powder samples. Prior to analysis, the instrument was mixed with two cycles to obtain a homogeneous structure of the sample. Then 3 analysis cycles were performed and the cohesion coefficient was calculated by the upward movement of the blade at $50 \mathrm{~mm} . \mathrm{s}^{-1}$ speed [10].

Cohesion coefficient, cake strength, and powder flow speed dependency tests were calculated with Texture Exponent 32 software (Stable Micro Systems, Surrey, UK).

\subsection{Statistical Analysis}

One way analysis of variance (ANOVA) and Tukey test was applied to the data to analyze the difference between the means using a statistical program (Minitab 18, Minitab Inc., USA).

\section{Results}

\subsection{Tapped, Loose Bulk density, Carr index and Hausner Ratio}

The difference in the composition of food products lead to changes in bulk and tapped bulk density of the products. In particular, bulk density and tapped bulk density are important in product characterization, especially when considering the compression condition during storage. Table 1 illustrates the loose bulk density, tapped bulk density, Carr index and Hausner ratio of the cocoa having different fat compositions. 
Table 1. The loose, tapped bulk density, Carr index and Hausner ratio of the samples

\begin{tabular}{lllll} 
Samples & $\begin{array}{l}\text { Loose Bulk Density } \\
(\mathbf{g} / \mathbf{m L})\end{array}$ & $\begin{array}{l}\text { Tapped Bulk } \\
\text { Density }(\mathbf{g} / \mathbf{m L})\end{array}$ & Carr index & Hausner Ratio \\
\hline LFC & $0.346 \pm 0.004^{\mathrm{c}}$ & $0.398 \pm 0.001^{\mathrm{c}}$ & $12.186 \pm 1.105^{\mathrm{c}}$ & $1.138 \pm 0.014^{\mathrm{c}}$ \\
$\mathrm{RFC}$ & $0.375 \pm 0.005^{\mathrm{b}}$ & $0.441 \pm 0.003^{\mathrm{b}}$ & $15.065 \pm 0.848^{\mathrm{b}}$ & $1.177 \pm 0.012^{\mathrm{b}}$ \\
FFC & $0.423 \pm 0.001^{\mathrm{a}}$ & $0.542 \pm 0.002^{\mathrm{a}}$ & $22.029 \pm 0.354^{\mathrm{a}}$ & $1.283 \pm 0.005^{\mathrm{a}}$ \\
\hline
\end{tabular}

* Means that do not share same letter are significantly different. LFC: low fat cocoa, RFC: reduced fat cocoa, FFC: full fat cocoa.

According to this table, the maximum values of loose and tapped bulk density, Carr index and Hausner ratio was recorded in FFC, while the minimum data were observed in sample LFC. The differences in fat composition caused statistically significant differences in the important bulk powder properties of cocoa samples.

\subsection{Powder flowability test results}

Three powder tests were performed in order to characterize the flowability of cocoa powder samples. These were the cohesion test, powder flow speed dependency test, and caking test, respectively. Figure 1 represented the cohesion index values of cocoa samples.

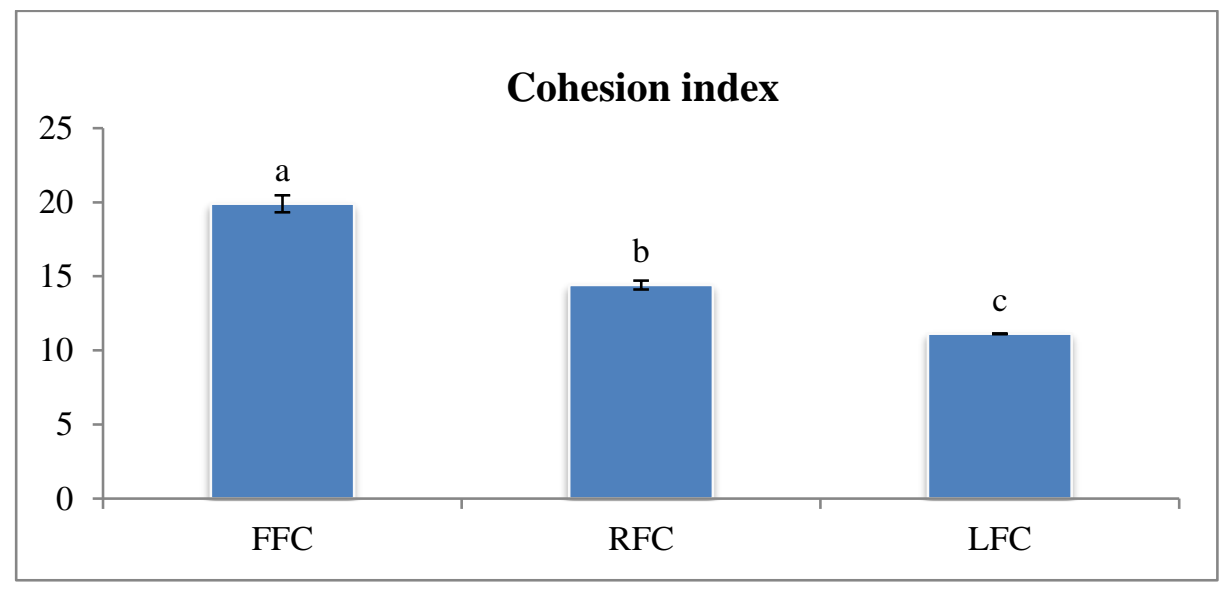

Figure 1. Cohesion index values of cocoa samples. Means that do not share same letter are significantly different $(\mathrm{p}<0.05)$. FFC: full fat cocoa; LFC: low fat cocoa, reduced fat cocoa.

The maximum cohesion index value was recorded as $19.897 \pm 0.574$ at the full-fat cocoa sample. According to the cohesion index value of the sample, FFC samples can be classified as extremely cohesive/ hardened, RFC samples was cohesive and LFC samples could be defined as easyflowing powders [11]. When the cocoa powders were compared, it was determined that the low fat containing cocoa powders had easy flow with the cohesion index value of $11.12 \pm 0.026$. The change in fat composition affected the cohesion index value and thus the flow properties of the cocoa powders.

In PFSD tests, the compaction coefficients were calculated from the positive area under the force/distance curve in each compaction cycle. An example graph of PFSD test was given in 
Figure 2 obtained from the texture analyzer software for each cocoa powder samples.

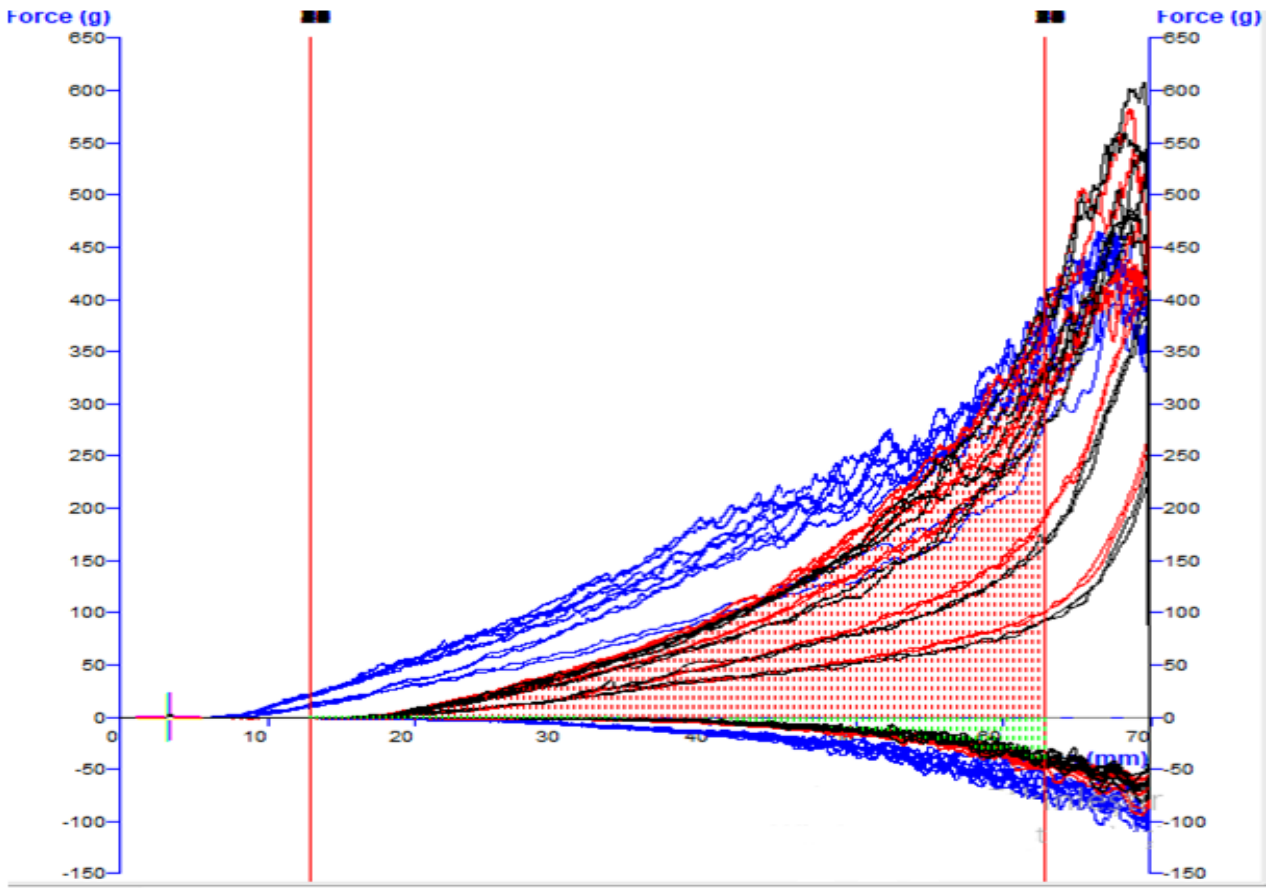

Figure 2. Example graph of the powder flow speed dependency test results of cocoa samples.

FFC: full fat cocoa; LFC: low fat cocoa, reduced fat cocoa

The compaction coefficients of the cocoa samples, which were shown by increasing test rates for the calculation of the compaction coefficient values, were shown in Figure 3. Among the cocoa powders containing different fat composition, the lowest compaction coefficient was determined in FFC where highest fat content was attributed in the composition. Cocoa powder samples with a lower amount of fat had higher compaction coefficient than the samples containing a high amount of fat in their composition. While the test speed increased from $50 \mathrm{~mm} / \mathrm{s}$ to $100 \mathrm{~mm} / \mathrm{s}$, the more drastic reduction in the compaction coefficient was observed.

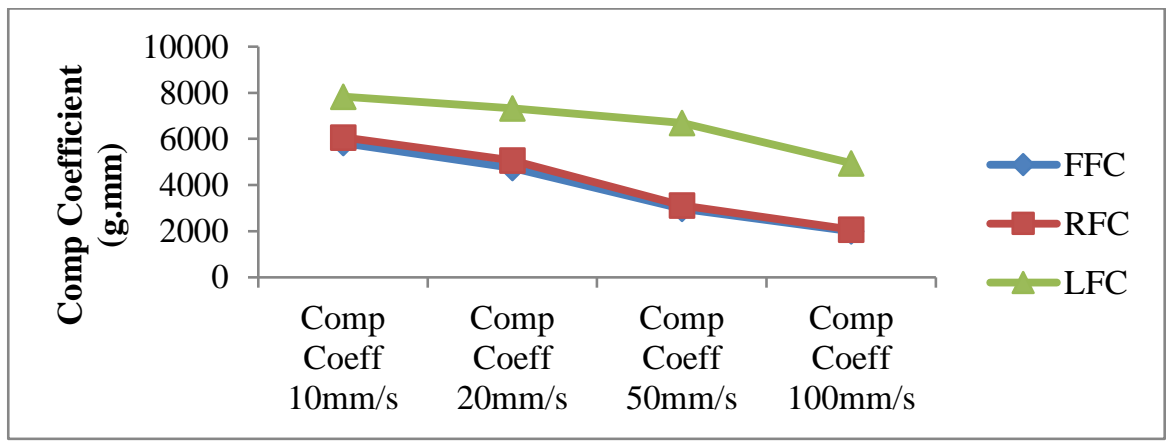

Figure 3. Powder flow speed dependency test results of cocoa samples.

FFC: full fat cocoa; LFC: low fat cocoa, reduced fat cocoa.

In Table 2, flow stability values obtained from PFSD test of the cocoa samples were given. The 
flow stability value is interpreted whether it was below or above 1 . If the flow stability value was less than 1 indicates that there was granulation during the analysis and if that it was higher than 1 indicates that the granulation would not take place [10]. According to the flow stability index values of FFC, RFC and LFC samples were found to be 1.02, 1.07 and 1.03, respectively. As the flow stability value of the cocoa samples was higher than 1 , it was concluded that no granulation took place during storage or transportation of the products.

Table 2. Flow stability and mean cake strength of the samples

\begin{tabular}{ccc}
\hline Samples & Flow stability & Mean cake strength $(\mathbf{g})$ \\
\hline FFC & $1.02 \pm 0.035^{\mathrm{a}}$ & $207.96 \pm 0.927^{\mathrm{a}}$ \\
RFC & $1.07 \pm 0.020^{\mathrm{a}}$ & $164.12 \pm 1.750^{\mathrm{b}}$ \\
LFC & $1.03 \pm 0.033^{\mathrm{a}}$ & $110.42 \pm 1.706^{\mathrm{c}}$ \\
\hline * Means that do not share same letter are significantly different. \\
LFC: low fat cocoa, RFC: reduced fat cocoa, FFC: full fat cocoa
\end{tabular}

Caking is a problematic condition that product undesirably combines to form hard agglomerates [3]. Caking causes losses in the functional properties and quality of the product [12]. The results of the caking test as mean cake strength were shown in Table 2. When the results of the analysis were examined, it was seen that the FFC sample had higher mean cake strength. With this data, the high fat containing cocoa powder was thought to be more prone to agglomeration during storage. Statistical analysis showed that there was a significant difference $(p<0.05)$ among the different fat-containing cocoa samples regarding their mean cake strength values.

\section{Discussion}

Bulk density is an important parameter for the particulate powders to measure packing characteristics [13]. The bulk density of the cocoa powders which contained different fat was statistically different from each other and the loose bulk density values were $0.346-0.423 \mathrm{~g} / \mathrm{mL}$. There was a relationship between the fat content and bulk densities of the samples. As the fat content increased, the bulk density increased also. In a previous study, the bulk density of cocoa powder was reported to range from 0.69 to $0.83 \mathrm{~g} / \mathrm{mL}$ [14].

The Carr index is used for the classification of flow properties of powder [15]. Flow properties of powders were affected by the particle size, density, particle shape, electrostatic charge, moisture content and composition of the product. The Carr index (Table 1) of the samples was $22.029 \pm 0.354 \%$ for the full-fat cocoa and $12.186 \pm 1.105 \%$ for the low-fat cocoa. According to the CI value evaluation scale [16], FFC was classified as fair flowing, RCF was good flowing and very good flowing powder.

The Hausner ratio is a value related to the compaction in other words cohesion of the powder. It expresses the tendency of dust particles to stick together [17]. When the samples classified based on the HR evaluation scale [16], LFC and RCF fallen into the low cohesive group, while the FFC was fallen into the intermediate cohesive group.

The cohesion test was used to determine the cohesion coefficient and cohesion index. Cohesion is the tendency of powder particles to stick together and agglomerate. The test starts with 2 cycles to obtain a homogeneous structure and ready for testing, and then ends with 3 cycles to measure 
cohesion properties. The cohesion coefficient is determined at a rate of $50 \mathrm{~mm} \cdot \mathrm{s}^{-1}$ in the decompression step as the blade moves upward in the column. The cohesion coefficient was calculated from the negative area under the force/distance curve. The cohesion index ratio is determined as the cohesion coefficient/sample weight. The low cohesion index is an indicator of non-cohesive free-flowing powders while the high cohesion coefficient was an indicator of cohesive and poor flowing powders [18]. Based on the cohesion index values of the cocoa powders, the FFC, RFC and LFC samples were fallen into the extremely cohesive, cohesive and easy-flowing powder group, respectively.

The PFSD test consists of 5 sets at increasing speeds $\left(10,20,50,100 \mathrm{~mm} \cdot \mathrm{s}^{-1}\right)$. The compaction coefficients are calculated from the positive area under the force/distance curve in each compaction cycle. The physics of compaction can simply be expressed as compaction and coupling of two phases (solid and gas) due to the applied force [19]. If the compaction coefficient decreases with the increase in flow rate, it means the powder will free flow. The flow stability index is determined by the ratio of the coefficient of compression in the first and last phases (10 $\left.\mathrm{mm} . \mathrm{s}^{-1}\right)$. The flow stability index close to 1 indicates no significant change during the test. If the flow stability index is less or higher than 1, the sample flow behavior will change during the test. This change may occur due to abrasion of powder particles or breakage of agglomerated particles. As a result of PFSD analysis results, the flow stability values of samples exhibited that no granulation took place during storage or transportation of the cocoa samples as the value of flow stability was close to 1 .

Caking is a negative phenomenon that can be defined as the conversion of amorphous food powders into an agglomerated undesirable quality particles and leads functional losses [20]. The cake strength value was influenced by several factors, such as packaging efficiency interaction between particles and moisture content of the product. If the powder has a high tendency to agglomerate, the cake strength and means cake strength values would be relatively high [21]. According to the mean cake strength values of cocoa powders, the mean cake strength was increased as the fat content of the powders increased. Therefore, it would not wrong to speculate that the higher fat composition would lead to the undesirable caking of the cocoa powders.

\section{Conclusions}

The results of this study revealed a great diversity in cohesive properties and flowability for cocoa powders in the initial fat content. At low-fat content, the bulk properties were found to significantly contribute to cohesive properties and flowability. Due to the hydrophobicity of fat molecules on cocoa powders, the flowability and cohesion properties at high-fat content was found to be partly dependent on physicochemical and biochemical mechanisms. It can be assumed that the biochemical surface composition is more relevant than the bulk composition of cocoa to evaluate its flowability and cohesive properties. As a result of this work, it could be concluded that the biochemical surface composition of food products may alter the flowability, therefore it should be considered while designing new products. 


\section{References}

[1] Didiş, M.C., Investigation of Natural and Processed Cocoa and Cocoa Containing Products for Their Antioxidant Capacity and Phenolic Compounds, in Middle East Technical University. 2015, Middle East Technical University: Ankara.

[2] Bootello, M.A., et al., Evaluation of high oleic-high stearic sunflower hard stearins for cocoa butter equivalent formulation. Food chemistry, 2012. 134(3): p. 1409-1417.

[3] Zafar, U., et al., A review of bulk powder caking. Powder Technology, 2017. 313: p. 389401.

[4] Foster, K.D., J.E. Bronlund, and A.T. Paterson, Glass transition related cohesion of amorphous sugar powders. Journal of Food Engineering, 2006. 77(4): p. 997-1006.

[5] Perez-Munoz, F. and R. Flores, Particle size of spray-dried soymilk. Applied engineering in Agriculture, 1997. 13(5): p. 647-656.

[6] Fitzpatrick, J., et al., Glass transition and the flowability and caking of powders containing amorphous lactose. Powder Technology, 2007. 178(2): p. 119-128.

[7] Tatar, F., Balık (Engraulis encrasicolus L.) Yağının Mikroenkapsülasyonunda Hemiselülozun Kaplayıcı Madde Olarak Kullanımı, in Science Enstitute. 2012, Ondokuz Mayıs University: Samsun.

[8] Turchiuli, C., et al., Oil encapsulation by spray drying and fluidised bed agglomeration. Innovative Food Science \& Emerging Technologies, 2005. 6(1): p. 29-35.

[9] Jan, S., S.I. Rafiq, and D. Saxena, Effect of physical properties on flow ability of commercial rice flour/powder for effective bulk handling. International Journal of Computer Applications, 2015. 975: p. 8887.

[10] Göksel Saraç, M., Production of Emulsifier from Rendering Waste Oil and Application Interfacial Rheological Properties in Model Food, in Graduate School of Natural and Applied Sciences 2018, Erciyes University: Kayseri.

[11] Abdullah, E., A. Salam, and A. Aziz, Cohesiveness and flowability properties of silica gel powder. Physics International, 2010. 1(1): p. 16-21.

[12] Benković, M., et al., Flow properties of commonly used food powders and their mixtures. Food and bioprocess technology, 2013. 6(9): p. 2525-2537.

[13] Shittu, T.A. and M.O. Lawal, Factors affecting instant properties of powdered cocoa beverages. Food Chemistry, 2007. 100(1): p. 91-98.

[14] Joel N., P.B., Deborah A., Chris U., Production and quality evaluation of cocoa products (plain cocoa powder and chocolate). American Journal of Food and Nutrition, 2013. 3(1): p. 31-38.

[15] Wolever, T., Relationship between dietary fiber content and composition in foods and the glycemic index. The American journal of clinical nutrition, 1990. 51(1): p. 72-75.

[16] Santhalakshmy, S., et al., Effect of inlet temperature on physicochemical properties of spray-dried jamun fruit juice powder. Powder Technology, 2015. 274: p. 37-43.

[17] Takka, S., Acartürk F., Ağabeyoğlu İ,, Çelebi N., Beğim T., Beğim Z, Modern Farmasötik Teknoloji, in Ecza Akademi. 2009: Ankara. p. 120-140

[18] Landillon, V., et al., Flowability, cohesive, and granulation properties of wheat powders. Journal of Food Engineering, 2008. 86(2): p. 178-193.

[19] de Freitas Eduardo, M. and S.C. da Silva Lannes, Use of texture analysis to determine compaction force of powders. Journal of food engineering, 2007. 80(2): p. 568-572. 
[20] Aguilera, J., J. del Valle, and M. Karel, Caking phenomena in amorphous food powders. Trends in Food Science \& Technology, 1995. 6(5): p. 149-155.

[21] Benkovic, M. and I. Bauman, Flow properties of commercial infant formula powders. World Academy of Science, Engineering and Technology, 2009. 54(6): p. 495-499. 